\title{
Explanatory Style of Schizophrenic and Depressed Outpatients $^{1}$
}

\author{
Robert J. Silverman ${ }^{2,4}$ and Christopher Peterson ${ }^{3}$
}

We administered an Attributional Style Questionnaire (ASQ) to several outpatient groups-paranoid schizophrenics $(\mathrm{n}=32)$, nonparanoid schizophrenics $(\mathrm{n}=30)$, and depressives $(\mathrm{n}=30)$-as well as to a normal comparison group of community college students $(\mathrm{n}=30)$. Depressives evidenced a more pessimistic explanatory style than paranoid and nonparanoid schizophrenics and normals. Six months later, among those outpatients experiencing hassles, individuals who attributed good events to stable, global, and internal causes were functioning somewhat better than those who attributed good events to unstable, specific, and external causes. We operationalized explanatory "flexibility" as the range of scores on the ASQ and found that outpatients with larger range scores for bad events (presumably showing more flexibility) functioned better than those having smaller range scores.

KEY WORDS: adjustment; attribution; depression; flexibility; schizophrenia.

\footnotetext{
${ }^{1}$ This article is based on the first author's doctoral dissertation, which was submitted to the Graduate Faculty of the New School for Social Research.

Subjects were recruited from Creedmoor Psychiatric Center, Harlem Valley Psychiatric Center, New York State Psychiatric Institute, Pilgrim Psychiatric Center, the Veterans Administration Medical Center at Northport, and LaGuardia and Queensborough Community Colleges. We wish to thank the subjects who participated in this project and the staff members who assisted. We are also grateful to Irving Bernstein and Nathan Kogan for their help and support. We especially wish to express our appreciation to Debbie Bruno for her invaluable suggestions, assistance, and encouragement.

${ }^{2}$ Creedmoor Psychiatric Center, Queens Village, New York 11427.

${ }^{3}$ University of Michigan, Ann Arbor, Michigan.

${ }^{4}$ Please address all correspondence to Robert Silverman, Department of Psychology, Creedmoor Psychiatric Center, 80-45 Winchester Boulevard, Queens Village, New York. 11427.
} 
According to the reformulation of the learned helplessness model of depression, causal explanations about bad events influence the deficits that may follow in their wake (Abramson, Seligman, \& Teasdale, 1978). Stable explanations ("It's going to last forever") lead to more chronic difficulties than unstable explanations. Global explanations ("It's going to affect everything I do") result in more pervasive problems than specific explanations. And internal explanations ("It's my doing") result in greater loss of selfesteem than external explanations. Individuals who explain bad events in a characteristic way are said to have an explanatory style, and a pessimistic style-in which bad events are attributed to stable, global, and internal causes-has been proposed as a risk factor for helplessness following bad events.

The helplessness reformulation has been investigated most frequently with respect to depression, because helplessness deficits are analogous to common depressive symptoms (Seligman, 1975). Literally hundreds of studies have established a cross-sectional correlation between pessimistic explanatory style and the extent of depression (Sweeney, Anderson, \& Bailey, 1986). However, research into other aspects of the helplessness reformulation has been comparatively meager (Peterson, 1991). The present study explored three of these neglected areas.

First was the model's specificity to depression. According to theory, a pessimistic explanatory style should be more closely associated with depression than it is with other psychological disorders. Relatively few studies have compared the explanatory style of individuals with different problems, and findings to date are inconsistent, sometimes showing specificity and sometimes not (Peterson, Maier, \& Seligman, 1993). The typical studies investigating specificity have compared depressives with individuals suffering one or another anxiety disorder. In light of the extensive comorbidity of depressive and anxiety disorders (Maser \& Cloninger, 1990), such studies may be inherently ambiguous.

A better strategy is to choose a more distinct comparison group, such as schizophrenics (cf. Raps, Peterson, Reinhard, Abramson, \& Seligman, 1982). So, in the present research, we compared the explanatory style of depressed and schizophrenic outpatients. We also included a group of normal subjects. Within the group of schizophrenic outpatients, we distinguished between paranoid and nonparanoid individuals, anticipating in light of paranoid grandiosity and/or perceived threat that they might differ with respect to the internality vs. externality of their characteristic explanations.

The second neglected area of research the study explored was the role of explanatory style in predisposing good or bad adjustment. The helplessness reformulation is explicitly a process model, making claims about 
psychological processes that unfold over time (Abramson, Metalsky, \& Alloy, 1988). But most studies investigating the reformulation are cross-sectional. A contemporaneous correlation between explanatory style and adjustment is consistent with the reformulation but also with other possibilities (Peterson \& Seligman, 1984). A longitudinal study in which explanatory style is measured prior to the outcome of concern is a more informative design.

In the present research, we followed our outpatient subjects for 6 months, assessing their overall adjustment at the beginning and end of this period. Does explanatory style, measured at Time 1 , predict adjustment at Time 2, over and above initial levels of well-being? This approach has been used in several studies investigating the rise and fall of depressive symptoms (e.g., Needles \& Abramson, 1990), but no one to date has investigated the role of explanatory style in the adjustment of schizophrenic individuals.

Is there reason to think that explanatory style influences the adjustment of schizophrenics? An extreme interpretation of the helplessness model in terms of specificity might lead to the prediction that explanatory style pertains only to the well-being of depressed individuals, but this seems unreasonable. Helplessness is involved in many forms of complex behavior (Peterson et al., 1993), and we can expect explanatory style, as a distal influence on helplessness, to be widely pertinent as well. Indeed, helplessness can be recognized in the schizophrenic individual's passivity, diminished sense of control, failure to initiate or engage in appropriate instrumental activity, social withdrawal, blunted or flat affect, and so on.

The helplessness reformulation is a diathesis-stress model, proposing that a pessimistic explanatory style is problematic for an individual only when bad life events are encountered. Accordingly, we administered to our outpatient subjects at Time 2 measures of stressful events during the intervening months, anticipating that any link between explanatory style and adjustment would be most apparent among those subjects who had experienced at least some amount of stress.

The third neglected area this study concerned itself with was influences on helplessness other than those stressed in research to date. The helplessness reformulation directs the researcher's attention to the stability, globality, and internality of causal explanations, but these are not the only cognitive variables of potential importance (Peterson, 1991). For example, Wortman and Dintzer (1978) and Anderson (1980) have argued that the perceived controllability of an event importantly shapes how one reacts to it. In the present research, we asked not only about the stability, globality, and internality of an event's cause but also about the controllability of the event itself. 
Going further, a question can be raised about the degree to which individuals show any sort of explanatory style. Consider that some people are more consistent than others in how they explain disparate events (Peterson, 1991). Is the person who offers different explanations, as opposed to similar accounts, more sensitive to the nuances of given situations and hence more likely to act in adaptive fashion?

While an investigation of the veracity of particular causal explanations was beyond our abilities, we took a preliminary step in this direction by calculating for each of our subjects the range of causal explanations they offered for different events. We tentatively identified those individuals with a broad range as flexible and those with a narrow range as rigid. In keeping with a widespread consensus concerning the harmful effects of rigid thinking, we anticipated that our relatively flexible subjects would fare better than their more rigid counterparts (cf. Beck, Rush, Shaw, \& Emery, 1979; Ellis, 1973; Horney, 1937; Kogan \& Wallach, 1964; Lazarus, 1981; Meichenbaum, 1985; Millon, 1981; Moos, 1967, 1968; Patsiokas, Clum, \& Luscomb, 1973; Rogers \& Wright, 1975; Ruderman, 1986; Shapiro, 1965; Vaillant, 1977; Vinoda, 1966).

\section{METHOD}

\section{Subjects}

Outpatient subjects were recruited by contacting therapists and informing them of the general requirements of the study. Therapists nominated outpatients who seemed to fit the inclusion criteria and were willing to complete several questionnaires.

At Time 1, there were 124 subjects: 32 paranoid schizophrenics, 30 nonparanoid schizophrenics, 30 unipolar depressives, and 32 normal adults. In each category, exactly half of the subjects were male, half female. The clinical subjects were outpatients between the ages of 18 and 60. Most $(n$ $=85$ ) were attending a state psychiatric clinic or day program in New York City or Westchester County, although some $(n=7)$ were attending a Veterans Administration outpatient facility on Long Island. At Time 2, 89 of the 92 outpatients $(97 \%)$ participated. The three outpatients not studied at Time 2 were no longer in treatment.

Only included were outpatients who scored above an estimated IQ of 85, as estimated by the Jastak Vocabulary Test (Jastak \& Jastak, 1964). All subjects had completed two or more years of high school.

All of the schizophrenic outpatients and half of the depressive outpatients had been discharged from a psychiatric hospital within the previous 
4 years. In these cases, an outpatient was included only if there was agreement on the general category of diagnosis (i.e., schizophrenia vs. unipolar depression) on the admission note to the outpatient clinic and the discharge note from the last hospitalization. The remaining depressives had not been in a psychiatric hospital during the previous 4 years. For these individuals, agreement was required between the last two outpatient diagnoses.

Therapists of the outpatients had a minimum of a bachelor's degree in a mental health field and at least 5 years experience or, alternatively, a masters or more advanced degree in a mental health field.

The Maine Scale of Paranoid and Nonparanoid Schizophrenia was used to identify subtype of schizophrenia and to reduce the likelihood of misdiagnosis of depression (Magaro, Abrams, \& Cantrell, 1981). This instrument consists of two scales, each with five items, one measuring paranoid schizophrenia and the other nonparanoid schizophrenia. Each item requires a single symptom to be rated by researchers on a 5-point Likert scale. Ratings are summed to yield scores for paranoid and nonparanoid schizophrenia.

We examined both inpatient and outpatient medical records from the last 4 years in order to complete the Maine Scale. Interrater reliabilities were computed by having an experienced psychiatric social worker independently score information gathered and scored by us for 30 randomly selected patients. Alpha coefficients of .92 for the paranoid scale and .95 for the nonparanoid scale were obtained.

A cutoff score of 12 on the paranoid scale was used to identify paranoid schizophrenics, and a cutoff score of 10 on the nonparanoid scale was used to identify nonparanoid schizophrenia, with at least a 4-point difference between the paranoid and nonparanoid scales required in each case.

All schizophrenic outpatients met DSM-III criteria for schizophrenia and had exhibited symptoms for at least 6 months (American Psychiatric Association, 1980). Individuals included in the unipolar depressed group met DSM-III criteria for either major depressive episode or dysthymic disorder. To assure that individuals in the depressive group were not also schizophrenic, a depressive outpatient was only included if his or her Maine Scale scores were at or below 7 on the paranoid scale and 6 on the nonparanoid scale. Outpatients who had received diagnoses of bipolar disorder or schizoaffective disorder were not included.

The normal comparison subjects were students at LaGuardia and Queensborough Community Colleges, generally those attending evening classes. An individual was not included in this group if he or she had a history of psychiatric hospitalization or a score of 10 or above on the Beck Depression Inventory (BDI; Beck, Ward, Mendelson, Mock, \& Erbaugh, 1961). The students were also asked several questions about schizophrenic 
Table I. Characteristics of the Sample: Means and Standard Deviations (in parentheses)

\begin{tabular}{lcccc}
\hline & $\begin{array}{c}\text { Paranoid } \\
\text { schizophrenics }\end{array}$ & $\begin{array}{c}\text { Nonparanoid } \\
\text { schizophrenics }\end{array}$ & Depressives & Normals \\
\hline Age & $36.4(8.7)$ & $34.9(8.4)$ & $41.8(9.7)$ & $33.0(9.1)$ \\
IQ & $107(16)$ & $106(14)$ & $126(18)$ & $112(16)$ \\
Yearly income earned & & & & \\
$\quad$ from employment & $915(1697)$ & $1583(4927)$ & $9321(15287)$ & $16753(12166)$ \\
Years of education & $13.0(1.8)$ & $12.5(1.6)$ & $14.4(2.5)$ & $13.3(1.5)$ \\
\% Married & 6.3 & 6.7 & 26.7 & 15.6 \\
\hline
\end{tabular}

symptomatology and any treatment received for psychological problems. Several potential subjects were eliminated from the "normal" group because such procedures indicated the possible presence of disorder.

Table I presents the age, estimated IQ, income, education, and marital status of our sample. As can be seen, depressives had a higher IQ and more education than the other groups. They were also older. The income of depressives exceeded that of the schizophrenic groups but was less than that of normals. Paranoid and nonparanoid schizophrenics earned less money than normals.

\section{Procedure}

All subjects attended the Time 1 session. After completing the Jastak Vocabulary Test, they filled out the Beck Depression Inventory and a version of the Attributional Style Questionnaire (ASQ). Subjects then answered a questionnaire asking for demographic information. Six months later, outpatient subjects attended the Time 2 session, where they were given two measures of stress: the Social Readjustment Rating Scale (SRRS; Holmes \& Rahe, 1967) and the Hassles Scale (Kanner, Coyne, Schaefer, \& Lazarus, 1981). Subjects were tested individually, and one of the researchers read questionnaires aloud to each subject, who was provided with a copy to read simultaneously. Each subject was paid $\$ 10$ for participation. The therapists of the outpatients completed the Global Assessment Scale (GAS; Endicott, Spitzer, Fleiss, \& Cohen, 1976) at both Time 1 and Time 2.

\section{Measures}

$B D I$. The BDI is a self-report instrument consisting of 21 categories of symptoms, each a specific manifestation of depression and consisting of a graded series of statements reflecting the extent and severity of the symp- 
tom in question. Scores are summed to yield an overall estimate of the extent of depressive symptoms.

$A S Q$. The ASQ used in the present research was an expanded version of the original questionnaire described by Peterson et al. (1982). Subjects were presented with hypothetical events involving themselves, 10 good and $10 \mathrm{bad}$. They were asked to imagine each event happening and then to provide the "one major cause" of the event. The cause specified was then rated on 7-point scales reflecting its stability (vs. instability), globality (vs. specificity), and internality (vs. externality). The event itself was rated on a 7-point scale according to how helpless it would make the individual feel (vs. feeling in control).

Internal reliabilities as estimated by Cronbach's (1951) alpha coefficients were satisfactory. For good events, alphas were .75 for stability, .76 for globality, .70 for internality, and .92 for helplessness. For bad events, the analogous alphas were $.85, .85, .72$, and .88 . Composite explanatory style scores were formed separately for good events and bad events by averaging the relevant ratings for stability, globality, and internality. For the good event composite, the alpha coefficient was .85 , and for the bad event composite, .89 .

Range scores for each dimension were computed by calculating the difference between the two most extreme ratings along that dimension. We also calculated flexibility in another way: the sum of squared deviations of scores around the subject's mean score for a given dimension. In subsequent analyses, findings were similar for both indices of flexibility, but the range scores yielded slightly more robust results. In light of this, as well as for simplicity's sake, we preferred the range scores.

SRRS. The SRRS is a 43-item scale that assesses the occurrence of a variety of major life events. The respondent is asked whether each life event was experienced in the past 6 months. Each life event is weighted according to the amount of social readjustment it requires. These weighted values were summed in our study to provide a measure of overall stress. Two items on the SRRS were modified in keeping with inflation over the past several decades. The dollar amounts in the items "mortgage over $\$ 10,000$ " and "mortgage or loan less than $\$ 10,000$ " were changed to $\$ 20,000$.

Hassles Scale. The Hassles Scale is part of a larger instrument called the Hassles and Uplifts Scale. In contrast to the SRRS, the Hassles Scale measures everyday stresses, ranging from minor annoyances to more severe difficulties. The Hassles Scale presents the respondent with 117 hassles and asks whether each has occurred in the past month or not. If it did, the subject rates its severity on a 3-point scale. The scores which we report were the cumulated severity ratings. 
GAS. The GAS was used to measure coping and adjustment. We chose this measure because it could be applied to both depressive and schizophrenic individuals. The GAS is completed by an individual's therapist in terms of global functioning during the past week. Scores range from 1 (= needs constant supervision for several days to prevent hurting self or others) to 100 (= superior functioning in a wide range of activities). Intermediate ratings are explicitly defined for the therapist, and examples are provided.

\section{RESULTS}

Specificity. Because ANOVAs revealed significant effects of diagnostic group for the demographic variables of age, IQ, income, and education, an ANCOVA was performed, partialing the effects of these variables from the ASQ. However, the pattern of results obtained was essentially the same as that obtained with ANOVA, so we present only the ANOVA results. Similarly, covarying BDI scores on the ASQ for the three nondepressive groups did not substantially change the pattern of results, so we present only unadjusted means and findings based on them.

MANOVA was computed on the eight subscales of the ASQ, revealing a highly significant main effect of diagnostic group $(F=3.51, p<$ $.0005)$. The main effect of sex and the interaction of Group $\times$ Sex were not significant, so we combined results from males and females within each diagnostic group. Means of the ASQ dimensions and composites are shown in Table II, along with ANOVA results examining the effect of diagnostic group. Significant effects were found for seven of the eight subscales of the ASQ and for both composites.

Multiple-comparisons tests using the procedure of least significant difference (LSD) were used to contrast the diagnostic groups on the ASQ scores. These results are also shown in Table II. Depressives were different from the other three groups on most of the measures, particularly for bad events. As predicted by the helplessness reformulation, depressives evidenced the most pessimistic explanatory style, offering more stable, global, and internal attributions for bad events than either schizophrenics or normals. Further, depressives reported more helplessness for bad events than did either schizophrenics or normals.

For good events, the groups did not differ as much. However, depressives attributed these events to less stable causes than the other groups and reported more helplessness. Relative to paranoid schizophrenics and normals, depressives attributed good events to less internal causes and had lower scores on the composite measure. 
Table II. Mean Explanatory Style Scores ${ }^{a}$

\begin{tabular}{lccccc}
\hline & $\begin{array}{c}\text { Paranoid } \\
\text { schizophrenics }\end{array}$ & $\begin{array}{c}\text { Nonparanoid } \\
\text { schizophrenics }\end{array}$ & Depressives & Normals & $F(3,116)$ \\
\hline Good events & & & & & \\
Stability & $5.13^{\mathrm{a}}$ & $4.99^{\mathrm{a}}$ & $4.52^{\mathrm{b}}$ & $5.23^{\mathrm{a}}$ & $5.63^{b}$ \\
Globality & 4.67 & 4.32 & 4.75 & 4.86 & .13 \\
Internality & $5.20^{\mathrm{ab}}$ & $4.78^{\mathrm{cd}}$ & $4.48^{\mathrm{c}}$ & $4.97^{\mathrm{ad}}$ & $5.17^{\mathrm{c}}$ \\
Composite & $5.00^{\mathrm{ab}}$ & $4.70^{\mathrm{ac}}$ & $4.59^{\mathrm{c}}$ & $5.02^{\mathrm{bd}}$ & $3.71^{d}$ \\
Helplessness & $2.03^{\mathrm{a}}$ & $1.88^{\mathrm{a}}$ & $3.39^{\mathrm{b}}$ & $2.00^{\mathrm{a}}$ & $19.86^{b}$ \\
& & & & & \\
Bad events & $3.34^{\mathrm{a}}$ & $3.16^{\mathrm{a}}$ & $4.27^{\mathrm{b}}$ & $3.27^{\mathrm{a}}$ & $9.15^{b}$ \\
Stability & $3.40^{\mathrm{a}}$ & $3.17^{\mathrm{a}}$ & $4.62^{\mathrm{b}}$ & $3.41^{\mathrm{a}}$ & $11.16^{b}$ \\
Globality & $5.20^{\mathrm{a}}$ & $4.78^{\mathrm{a}}$ & $4.48^{\mathrm{b}}$ & $4.97^{\mathrm{a}}$ & $4.57^{\mathrm{a}}$ \\
Internality & $3.48^{\mathrm{a}}$ & $3.44^{\mathrm{a}}$ & $4.45^{\mathrm{b}}$ & $3.48^{\mathrm{a}}$ & $13.57^{b}$ \\
Composite & $3.99^{\mathrm{a}}$ & $3.39^{\mathrm{b}}$ & $4.88^{\mathrm{c}}$ & $3.75^{\mathrm{ab}}$ & $10.34^{b}$ \\
Helplessness & & &
\end{tabular}

${ }^{a}$ Note: Means in a row with different roman letter superscripts are significantly different $(p<$

.05 ) by least significant difference procedure (see text). Italicized superscripts (indicating footnotes) refer to probabilities for univariate analyses of variance.

${ }^{b} p<.001$.

${ }^{c} p<.01$.

${ }^{d} p<.05$.

For the most part, the schizophrenic groups did not differ from the normal comparison group with respect to the ASQ measures. And the two schizophrenic groups usually did not differ from one another. However, paranoid schizophrenics were more internal for good events than nonparanoid schizophrenics, and they reported more helplessness with respect to bad events.

Explanatory Style and Adjustment. If attributional factors play a role in the adjustment of schizophrenics and depressives, then ASQ scores characteristics at Time 1 should predict level of adjustment at Time 2, above and beyond level of adjustment at Time 1. To investigate this, standardized residual gain scores on the $\mathrm{GAS}^{5}$ were calculated to estimate change in level of functioning over the 6-month period, and correlations were computed between these scores and the ASQ measures. In our analyses, we partialed out group membership by creating two dummy variables (to account for the three diagnostic groups).

We performed these analyses not only for the total outpatient sample but also for subsamples of outpatients who exceeded certain minimum values on the scales ${ }^{6}$ measuring stress: the SRRS and the Hassles Scale. Specifically, we looked at subjects who fell in the top three-quarters of the

${ }^{5}$ The outpatient groups did not differ on GAS scores at Time 1 (overall mean $=48.37$ ). At Time 2, depressives scored higher (mean $=54.34$ ) than either paranoid schizophrenics (mean $=45.81$ ) or nonparanoid schizophrenics (mean $=46.27$ ).

${ }^{6}$ Scores on the SRRS and the Hassles Scale did not correlate with residual gain scores. 
sample on these measures. There are alternative ways of testing the diathesis-stress hypothesis, and our decision to look at the top three-quarters was somewhat arbitrary. We wished to preserve adequate degrees of freedom, and we saw no reason to create a product term-Explanatory Style $x$ Stress-as some researchers have done, because there is no theoretical basis for believing that the degree of stress interacts with explanatory style to influence adjustment.

Contrary to the learned helplessness reformulation, few of the explanatory style scores predicted adjustment. Perceived helplessness for bad events was to some degree associated with a worsening of adjustment, in the total outpatient sample ( $r=-.19, p<.05$, one-tailed) but not in the subsample of individuals reporting the most hassles or the most major life events. The composite score for good events to some degree predicted an improving of adjustment in the outpatient sample, but only when analyses were confined to the three-quarters of outpatients experiencing the most hassles $(r=.24, p<.05$, one-tailed). So, subjects who explained good events with more stable, global, and internal causes tended to improve somewhat, whereas subjects who explained good events with unstable, specific, and external causes tended to decline somewhat. Explanatory style scores were similarly associated with GAS scores in the different outpatient groups.

Flexibility and Adjustment. We carried out similar analyses with our measures of explanatory flexibility, additionally partialing out mean ASQ scores. Range scores, particularly for bad events, proved to be consistent predictors of improved adjustment in the outpatient sample. ${ }^{7}$ The composite range score for bad events to some degree predicted residual gain scores for the total sample $(r=.21, p<.05$, one-tailed), and more powerfully when analyses were limited to subjects scoring in the top three-quarters on the Hassles Scale ( $r=.40, p<.001$, one-tailed). In this latter case, range scores for all three attributional subscales were significant predictors: stability $(r=.27, p<.03$, one-tailed), globality $(r=.35, p<.004$, one-tailed), and internality ( $r=.26, p<.03$, one-tailed). Outpatients whose attributions for bad events showed a greater range-presumably indicating greater flexibility-tended to improve over 6 months, whereas those with a more restricted range tended to decline. Focusing on the subsample of outpatients scoring highest on the SRRS did not increase the predictive power of the flexibility measures. Range scores for good events were not related

${ }^{7}$ For the most part, range scores did not differ across the outpatient groups. The only statistically significant difference was that depressives had wider ranges than schizophrenics for stability of positive events. 
to adjustment in any of the analyses. Range scores were similarly associated with GAS scores in the different outpatient groups.

\section{DISCUSSION}

The results of this research extend an attributional perspective on psychopathology in several ways. First, depressives were more likely than schizophrenics or normals to invoke stable, global, and internal attributions for bad events. The explanatory style of schizophrenics was much the same as that of normals. Our results therefore support the reformulated model by showing that a pessimistic explanatory style is specific to depression.

Second, paranoid and nonparanoid schizophrenics differed on only a few of the attributional measures. Paranoid schizophrenics were more internal for good events than nonparanoid schizophrenics and more helpless with respect to bad events. Both of these differences make sense in light of the typical content of paranoid ideation: grandiosity coupled with perceived threat.

Third, explanatory style played some role in predisposing adjustment. However, it was explanatory style for good events rather than bad events that predicted subsequent well-being, and only weakly at that. In any event, this finding is at odds with the helplessness reformulation, which stresses explanatory style for bad events. As Needles and Abramson (1990) have suggested, perhaps the onset of problems is under the sway of explanatory style for bad events, whereas recovery is influenced by explanatory style for good events. The present data do not allow these possibilities to be fully tested. Needed is a longitudinal investigation unlike any undertaken to date, in which individuals are studied before, during, and after psychological difficulties.

Fourth, as Anderson (1980) and others have suggested, an individual's perceived control over events influenced his or her adjustment. Research within the helplessness tradition has tended to neglect perceptions of control, despite the importance accorded to them in theory. The present results imply that the tendency to see bad events as out of one's control may be more important in predicting adjustment than the tendency to offer stable, global, and internal explanations for these events. Just what should be subsumed by the term "explanatory style" deserves further scrutiny.

Fifth, explanatory flexibility as operationalized in terms of different explanations for different events proved to be a consistent predictor of subsequent adjustment, particularly among those subjects who had experienced some degree of recent stress. We speculate that flexibility measured in this way may indicate the individual's tendency to take into account situational 
constraints and influences in offering explanations for events; accordingly, the flexible individual is better able to adjust than the rigid individual.

Said another way, perhaps any explanatory style-pessimistic or optimistic-is less useful than a flexible approach to explaining events (cf. Peterson \& Bossio, 1991; Seligman, 1991). Previous discussions of explanatory style have suggested that therapy should change an individual's characteristic explanations from pessimistic to optimistic (e.g., Seligman, 1981), but the present results imply that this is too simple a goal. Instead, explanations should become more consistent with the evidence that the world offers (cf. Beck et al., 1979).

Small subsample sizes limited the analyses we could do within diagnostic groups, but there was no apparent evidence that explanatory style or flexibility was differentially relevant to the adjustment of depressives vs. schizophrenics. So, the specificity of a pessimistic explanatory style to depression seems to refer to mean scores but not correlates. Attributional characteristics may well work the same in different groups, implying that they are generally important.

The present research has several limitations that must be acknowledged. Although we used conservative criteria for assigning individuals to diagnostic groups, we did so by relying to a great extent on information gleaned from their medical charts. There are obvious pitfalls to this procedure, and we worry in particular about the possibility that secondary diagnoses somehow confounded the results. Relatedly, due to the recruitment procedure, we suspect that our sample was not entirely representative of schizophrenic and depressive outpatients, being skewed somewhat toward better-functioning individuals.

Although previous research has shown that the GAS can be reliable (Endicott et al., 1976), its reliability in the present sample is unknown because it was completed only by a single rater for each subject. We chose this instrument because we wished to have a comparable measure for our depressive and schizophrenic subjects, but then decided that only the individual's therapist was able to complete it. Further, the ability of the GAS to detect the sorts of changes influenced by attributions is not clear, and the caution that should always be brought to bear on interpreting "negative" results should only be increased.

In sum, the present research investigated the explanatory tendencies of depressive and schizophrenic outpatients. Predictions of the attributional reformulation of helplessness theory were partly supported, partly not. Nonetheless, the pattern of attributional results was coherent and suggest that further investigation, among schizophrenics as well as depressives, would be profitable. 


\section{REFERENCES}

Abramson, L. Y., Metalsky, G. I., \& Alloy, L. B. (1988). The hopelessness theory of depression: Does the research test the theory? In L. Y. Abramson (Ed.), Social cognition and clinical psychology: A synthesis (pp. 33-65). New York: Guilford Press.

Abramson, L. Y., Seligman, M. E. P., \& Teasdale, J. D. (1978). Learned helplessness in humans: Critique and reformulation. Journal of Abnormal Psychology, 87, 49-74.

American Psychiatric Association (1980). Diagnostic and statistical manual of mental disorders (3rd ed.). Washington, DC: Author.

Anderson, C. A. (1980). Motivational and performance deficits as a function of atributional style. Unpublished doctoral dissertation, Stanford University.

Beck, A. T., Rush, A. J., Shaw, B. F., \& Emery, G. (1979). Cognitive therapy of depression. New York: Guilford Press.

Beck, A. T., Ward, C. H., Mendelson, M., Mock, J., \& Erbaugh, J. (1961). An inventory for measuring depression. Archives of General Psychiatry, 4, 561-571.

Cronbach, L. J. (1951). Coefficient alpha and the internal structure of tests. Psychometrika, $16,297-334$.

Ellis, A. (1973). Humanistic psychotherapy: The rational-emotive approach. New York: McGraw-Hill.

Endicott, J., Spitzer, R. L., Fleiss, J. L., \& Cohen, J. (1976). The Global Assessment Scale: A procedure for measuring overall severity of psychological disturbance. Archives of General Psychiatry, 33, 766-771.

Holmes, T. H., \& Rahe, R. H. (1967). The social readjustment rating scale. Journal of Psychosomatic Research, 11, 213-218.

Horney, K. (1937). The neurotic personality of our time. New York: Norton.

Jastak, J. F., \& Jastak, S. R. (1964). Short forms of the WAIS and WISC vocabulary subtests. Journal of Clinical Psychology, 20, 167-199.

Kanner, A. D., Coyne, J., Schaefer, C., \& Lazarus, R. S. (1981). Comparison of two models of stress measurement: Daily hassles and uplifts versus major life events. Journal of Behavioral Medicine, 4, 1-39.

Kogan, N., \& Wallach, M. A. (1964). Risk taking. New York: Holt, Rinehart, \& Winston.

Lazarus, R. (1981). The stress and coping paradigm. In C. Eisdorfer (Ed.), Models for clinical psychopathology (pp. 177-217). Englewood Cliffs, NJ: Prentice-Hall.

Magaro, P. A., Abrams, L., \& Cantrell, P. (1981). The Maine Scale for Paranoid and Nonparanoid Schizophrenia: Reliability and validity. Journal of Consulting and Clinical Psychology, 49, 438-447.

Maser, J. D., \& Cloninger, C. R. (Eds.) (1990). Comorbidity of mood and anxiety disorders. Washington, DC: American Psychiatric Press.

Meichenbaum, D. (1985). Stress innoculation training. New York: Pergamon Press.

Millon, T. (1981). Disorders of personality. New York: John Wiley \& Sons.

Moos, R. (1967). Differential effects of ward settings on psychiatric patients. Journal of Nervous and Mental Disease, 145, 272-283.

Moos, R. (1968). Situational analysis of a therapeutic community milieu. Journal of Abnormal Psychology, 73, 49-61.

Needles, D. J., \& Abramson, L. Y. (1990). Positive life events, attributional style, and hopefulness: Testing a model of recovery from depression. Journal of Abnormal Psychology, 99, 156-165.

Patsiokas, A. T., Clum, G. A., \& Luscomb, R. L. (1979). Cognitive characteristics of suicide attempters. Journal of Consulting and Clinical Psychology, 47, 478-484.

Peterson, C. (1991). Meaning and measurement of explanatory style. Psychological Inquiry, 2, 1-10.

Peterson, C., \& Bossio, L. M. (1991). Health and optimism. New York: Free Press.

Peterson, C., Maier, S. F., \& Seligman, M. E. P. (1993). Leamed helplessness: A theory for the age of personal control. New York: Oxford University Press. 
Peterson, C., \& Seligman, M. E. P. (1984). Causal explanations as a risk factor for depression: Theory and evidence. Psychological Review, 91, 347-374.

Peterson, C., Semmel, A., von Baeyer, C., Abramson, L. Y., Metalsky, G. I., \& Seligman, M. E. P. (1982). The Attributional Style Questionnaire. Cognitive Therapy and Research, 6, 287-299.

Raps, C. S., Peterson, C., Reinhard, K. E., Abramson, L. Y., \& Seligman, M. E. P. (1982). Attributional style among depressed patients. Joumal of Abnormal Psychology, 91, 102-108.

Rogers, R., \& Wright, E. W. (1975). Behavioral rigidity and its relationship to authoritarianism and obsessive-compulsiveness. Perceptual and Motor Skills, 40, 802.

Ruderman, A. J. (1986). Bulimia and irrational beliefs. Behaviour Research and Therapy, 24, 193-197.

Seligman, M. E. P. (1975). Helplessness: On depression, development, and death. San Francisco: Freeman.

Seligman, M. E. P. (1981). A learned helplessness point of view. In L. P Rehm (Ed.), Behavior therapy for depression: Present status and future directions (pp. 123-141). New York: Academic Press.

Seligman, M. E. P. (1991). Learned optimism. New York: Knopf.

Shapiro, D. (1965). Neurotic styles. New York: Basic Books.

Sweeney, P. D., Anderson, K., \& Bailey, S. (1986). Attributional style in depression: A meta-analytic review. Journal of Personality and Social Psychology, 50, 974-991.

Vaillant, G. E. (1977). Adaptation to life. Boston: Little, Brown, \& Company.

Vinoda, K. S. (1966). Personality characteristics of attempted suicides. British Journal of Psychiatry, 112, 1143-1150.

Wortman, C. B., \& Dintzer, L. (1978). Is an attributional analysis of the learned helplessness phenomenon viable?: A critique of the Abramson-Seligman-Teasdale reformulation. Journal of Abnormal Psychology, 87, 75-90. 